\title{
CENSO Y ETNICIDAD EN ESPAÑA. HISTORIA DE UNA AUSENCIA
}

\section{Census and Ethnicity in Spain. The Story of an Absence}

\author{
Pablo Estévez Hernández* \\ * Universidad de La Laguna (España) \\ bleris84@hotmail.com
}

\section{Palabras clave}

Censo Etnicidad

Inmigración

Demografía

Antropología

\section{Keywords}

Census

Ethnicity Inmigration Nationalities Demography Anthropology
Nacionalidad

\begin{abstract}
Resumen
En Europa ha comenzado a considerarse pragmáticamente el uso de categorías étnicas para recabar información censal. Esta consideración no ha venido sin litigio social y político, donde esta información "sensible" puede servir tanto en materia antidiscriminatoria como en catalogación y profusión de exclusión y racismo (estatal). En cualquier caso se ha comenzado a tomar en cuenta esta proyección censal debido a la perdida de visibilidad que tienen los inmigrantes de segunda generación una vez que obtienen nacionalidad, desapareciendo por tanto de las estadísticas en la forma de "extranjeros". Con distintos escenarios europeos, siempre contextualizados y en parte en conflicto con las herencias del pasado colonial, se ha llegado a disimiles resultados sobre esta posible inclusión. Este artículo se pregunta por una posible resistencia a la clasificación étnica en el censo nacional español, considerando su disposición cultural étnica interna (enfrascada en una tensión centro-periferia) y por las características propias del caso español, repasando su particularidad colonial y presentando un contexto comparativo con dos prominentes vecinos europeos.
\end{abstract}

\section{Abstract}

In Europe, the pragmatic use of ethnic categories has been considered for the collection of census information. This consideration is not free from social and political conflict, where this "sensible" information may be useful for antidiscrimination subjects as for classification and profusion of exclusion and (state) racism. In any case, these census projections have turned into consideration due to the visibility that certain second generation immigrants have once they are recognized as nationals, disappearing from statistics in the form of "foreigners". With different European scenarios, always in their context and partly in conflict with their own colonial past heritage, dissimilar results have been seen at the end of the search for this possible inclusion. This paper looks at a possible resistance to ethnic classification in the Spanish national census, taking in consideration its ethnic and cultural internal disposition (caught in a center-periphery tension) as for inner characteristics for the Spanish case, going through its colonial particularity and presenting a comparative context close to two outstanding European neighbors.

Estévez Hernández, P., 2015, "Censo y etnicidad en España. Historia de una ausencia, en Papeles del CEIC, vol. 2015/2, no 131, CEIC (Centro de Estudios sobre la Identidad Colectiva), Universidad del País Vasco, http://dx.doi.org/10.1387/pceic.13058 


\section{UN CENSO EN FALSO}

Y aquí estamos todos: en el censo. El trabajo del censo parece un proceso de sentido común, por el cual una neutral aritmética establece el cómputo total de los individuos que conforman el cuerpo de la Nación. La metáfora más usada en este terreno es la de la fotografía nacional, que, con un sólo disparo, consigue ver el esqueleto estadístico de un país. Por carencia, esa fotografía pasa a representar los últimos diez años del cuerpo de la Nación. Ese sentido común y esa metáfora fotográfica nos hacen pensar al censo como una herramienta clave para el Estado, para demógrafos y otros profesionales que tratan con la estadística y que entienden sus operacionalidades como neutrales y objetivas, aunque a veces comporten malas medidas y limitaciones. En sintonía con esa definición del censo, la escritora Margarita Rivére ha dicho con voz de alarma:

"Un censo mal hecho significa que el país entero está en falso respecto a su realidad. Como consecuencia, las políticas y acciones serán tendenciosas, equívocas, acaso erróneas (...) El asunto del censo nos pone ante un dilema totalmente contemporáneo: es quizás el único caso en el que la realidad real encerrada en unos números veraces es más valiosa e imprescindible que la representación de la realidad. El censo no admite ni sentido del humor, ni literatura, ni fantasías: es realidad pura, dura, pedestre. Y cuantificada, su misterio está en la verdad de esta cuantificación: el censo no puede ofrecer dudas. Es una flor exótica en medio de delirios tecnológicos y celtibéricos. Sin esa flor de la realidad real no hay interpretación que valga. $\mathrm{Ni}$ tampoco sociedad del conocimiento o soluciones imaginativas a los problemas cotidianos. El censo responde a la necesidad - $\tan$ demodéde saber dónde estamos en realidad" (Rivère, 2011: s/p. Cursivas en el original).

Esta defensa es consciente del estado zombi del censo (acentuado con la última crisis económica y social), como una institución incapaz de sintonizar con el contexto dislocado que provoca un sentido amplio de globalización (Estévez, 2013), una institución no tan eficaz pero simbólica. Como bien pudiera inducirse del artículo de Rivère, necesitamos el censo para saber quiénes somos; como nación y en un sentido cognoscitivo que ya empieza a ser clásico. Los antropólogos, por otra parte, indican que son las diferencias con otros contingentes humanos, establecidas en los límites, en la frontera, las que mejor nos 
indican quiénes somos (Barth, 1969). Ahora bien, ante el panorama de proliferación de etnicidades en la España de las últimas décadas, provocadas por los movimientos migratorios poscoloniales, y con un censo que se presenta como a-étnico, negándose a contar etnias, ¿no es posible que el censo mismo esté en falso con respecto a su "realidad real"? Por carencia de medios y de cuadro étnico, ¿el saber quiénes somos no estaría entonces sin contestación antropológicademográfica?

Lejos de situarse en el radicalismo empirista del que es participe Rivère, una nueva fuente crítica considera al censo no sólo como una herramienta, sino también como un artefacto o un dispositivo que traza, piensa e imagina a la Nación'. El censo (todos los censos) operaría siempre en función de un discurso con poder, sea este demográfico, colonial, nacional o, incluso, pos-nacional. Su sentido común se enfrenta primariamente con unas simples indicaciones:

"En un principio, la población de un país se corresponde con un número relativamente a-problemático. Pero no está finalmente determinado por el número de cuerpos encontrados en un territorio. Para empezar habría que decidir si considerar o no a los turistas, los foráneos legales o no, el personal militar y las personas con dos o más residencias y los de ciudadanías múltiples. Aún con esto, los números de la población dependerán del método para obtenerlos" (Porter, 1996: 33).

De estas problemáticas metodológicas podemos pasar, conducidos por diversos factores, a las cuestiones más epistemológicas que desafían su sentido neutral. En palabras de Bruce Curtis "Incluso el censo de población más consistentemente ejecutado depende de un particular imaginario acerca de seres humanos en un espacio-tiempo virtual. Implica relaciones sociales empíricas en función de capturarlas dentro de los confines de esa red (Curtis, 2001: 314, cursivas añadidas) ${ }^{2}$. Esta definición imaginaria-virtual del censo está en concordancia con la que da Benedict Anderson al respecto, como la de una ficción: "La ficción del

\footnotetext{
${ }^{1}$ La lista es larga, aquí propongo algunos pocos ejemplos: Appadurai (2005), Christopher (2002), Curtis (2001), Desrosièrs (2004), Nobles (2000) y Watts (2003).

${ }^{2}$ Es probable que la dependencia que tiene el censo con respecto a estos parámetros cambie. Recientemente se ha propuesto el llamado "censo continuado" que no pretende captar a la población en el tiempo de un día concreto, en el cual se levanta el censo, sino recogiendo información en periodos largos (años). Esto exige técnicas de muestreo más complejas. Véase la segunda revisión del informe de las Naciones Unidas (2010).
} 
censo es que todos están incluidos en él, y que cada quien tiene un lugar

-y solo uno- extremadamente claro. Nada de fracciones" (Anderson, 2006: 231).

Que todo esté incluido en el censo, esa ficción que capta seres humanos en un espacio-tiempo virtual, no quiere decir que metodológicamente seamos captados de igual manera. Al decir que el censo español actual no cuenta por etnias no implica que no se esté generando diferencia en el proceso censal y que no esté, en cierto sentido, excluyendo muchas cosas. Muy al contrario, la pregunta demográfica y la pregunta antropológica del "quiénes somos" se responde en conjunción. El censo es un dispositivo que, al moverse en las coordenadas de un determinado imaginario (nacional, colonial...), intuye que todos están en él tal cual lo piensa e imagina, esto es, con sus políticas de la diferencia incorporadas. Por lo tanto, el censo es la manera en la que el Estado-nación, su principal ejecutor, establece diferencias para controlar y coordinar un sentido nacional ( $y$, cabe decir, una población), excluyendo todo lo que es ajeno a esa idea.

Estudiar de esta manera el censo implica entenderlo como un dispositivo con cierta agencia para marcar estas diferencias. Se trata ciertamente de un proceso archivístico, que estudia sistemáticamente documentos y censos, pero que no los considera como un elemento apriorístico para la elaboración de ciertas teorías sociales, ni como fuentes incontigentes. Más bien, se estudia al censo como un nodo que articula un discurso. En este sentido, la metodología se vuelve más analítica, sin sobrevalorar su propio objeto de estudio e intentando vislumbrar los puntos operativos de la construcción de la diferencia (en la población).

\section{LA DIFERENCIA EN LOS CENSOS COLONIALES}

Pero hubo un tiempo en que en la demografía propia de los Estados nacionales europeos, el Otro, lo diferente, también era contado, pero para ello el censo se compartimentaba, creando un tipo especial llamado censo colonial. En los distintos periodos coloniales, impulsados por distintas potencias europeas, el censo fue un dispositivo clave para legitimar la diferencia entre las poblaciones coloniales y metropolitanas (Appadurai, 2005), donde se operaba muy frecuentemente con una nomenclatura racial para significar esa diferencia. Si con el tipo de 
registros estadísticos europeos sobre los propios europeos se puede hablar de gubernamentalidad ${ }^{3}$, en el caso de los censos coloniales quizás sea más preciso hablar de "gubernamentalidad racial", es decir, en "Ios procesos que hacen que una población, en un espacio político determinado, sea separada en distintos grupos usando el 'criterio racial', dejando a estos grupos sujetos a distintos modos de administración" (Watts, 2003: 30) algo que puede dar lugar a un "estado racial" que recrea una comunidad imaginada forzada a base de excluir lo que no está en su imaginario racial. La raza fue entonces el relato clave para "nuestras" diferencias con el mundo colonial, un mundo que había que someter y explotar y donde la base para justificar dicha intervención sobre los cuerpos y territorios de los colonizados estaban en los constructos de la Modernidad; en el relato científico de la diferencia racial de las poblaciones, en las ideas de supremacía cultural y, entre muchos otros artefactos, en el recuento del censo que servía tanto a efectos epistémicos como de control estatal. Como relato clave, entiendo la raza como una categoría discursiva que organiza la diferencia entre grupos humanos, anclada científicamente por la biología y la genética, pero no siendo más que un significante constituido socio-históricamente.

Para España, el último giro colonial se centró en África: en los territorios del golfo de Guinea y en África del norte ${ }^{4}$. En otro lado (Estévez, 2012) he argumentado que los censos coloniales en el Sáhara Español (un caso que podemos tomar como ejemplo aquí) comenzaron a realizarse tras una seria revalorización económica del territorio, con el descubrimiento

\footnotetext{
${ }^{3}$ El término fue acuñado por Michel Foucault y puede resumirse muy brevemente como la mentalidad o el modo de pensar la política en concordancia con la administración moderna que regula la vida de los súbditos.

${ }^{4}$ La genealogía que traza las políticas de la diferencia en España a través de un artefacto como el censo se expande en el tiempo y el espacio, contando con historias diversas. Aunque muchos ejemplos se hacen válidos para contrastar la teoría de esta genealogía, una especial atención debe ponerse en el caso de los censos realizados en las colonias africanas. La relación con las colonias africanas pasaba por la ambivalencia de una relación que no se reconocía como tal, sino como un estado de adscripción natural que no dominaba, ni recreaba, en apariencia, explotación económica, sino que establecía una serie de categorías donde incluso se llegaba a equiparar la nacionalidad metropolitana y colonial, re-construyendo la justificación de la presencia allá a través de distintas disciplinas, en el espacio y en el tiempo. Por eso, pese a la relativa continuidad y cercanía que traza con lo que podría llamarse la España poscolonial, las colonias africanas suponen también un ejemplo interesante para observar esta curiosa ambivalencia inherente a la política de la diferencia en la España actual.
} 
de fosfatos en el subsuelo. Este catalizador dio lugar a la sedentarización de tribus saharauis que pasaron a ser administradas y estudiadas con mayor insistencia, dando lugar a categorías étnico-raciales que resultarían ser la base de los censos. Por lo tanto, los censos coloniales estaban en sintonía con todo un proceso administrativo colonial, un ordenamiento de la diferencia y una manera de diferenciar efectivamente un ente metropolitano y otro colonial.

Luego de los imperios, after-empire: el desenlace, las nuevas dimensiones de la cultura, la nueva manera de entendernos globalmente, la melancolía... (Gilroy, 2008). Luego de los imperios coloniales moderno-europeos los censos siguieron contando "personas" tal cual lo habían hecho desde siempre (en casa). Como consecuencia de la barbarie nazi y su terror racial (entre otros muchos factores), la raza quedó desestimada de la información con base científica y por lo tanto su relato para clarificar y establecer diferencias y jerarquías humanas quedó desestimado con un consenso científico que supuso los pilares epistemológicos de la ONU y la UNESCO.

No obstante, hacia finales de siglo, la migración poscolonial revivió los debates de la diferencia étnica-racial en parte de los censos europeos. Buena parte de los debates sobre identidad cultural en Europa estuvieron centrados en la inmigración y la integración de los nuevos invitados o no de la Nación, un aspecto que, a su vez, replanteó cuestiones sobre la autoridad epistémica de Europa y Occidente y puso bajo óptica analítica su propia identidad (Hall, 1992). En España este proceso deconstructivo se vivió con posterioridad a otros países y con la intensidad de un proceso de modernización posfranquista que aconteció después de la descolonización formal; España se “blanqueaba" (Cornejo Parriego, 2007: 18).

Ciertamente, la inmigración desequilibraba el sentido nacional (Estévez, 2013). Manuel Lozano, teórico de derecho en los años cincuenta, lanzaba esta mirada a la problemática del estatus nacional del inmigrante poscolonial desde un mundo que todavía era "colonial":

"El mundo civilizado, superficialmente dividido, tenía un foco común en sus costumbres creencias y sus leyes; hoy con el acceso de los pueblos orientales y africanos, se presenta un nuevo factor capaz de cambiar las características étnicas si se deja abierta la inmigración y buen número de indígenas viene a establecerse a la metrópoli. Pero este problema no se ha 
presentado en España, país de natalidad expansiva. Con todo no está demás decir que el tratamiento a este respecto de los súbditos y protegidos ha de ser análogo al de los extranjeros" (Lozano, 1955: 111).

Por otra parte, en Gran Bretaña y Francia (las dos mayores potencias imperiales del siglo pasado) hubieron debates sobre la introducción de categorías étnicas en sus censos, que seguían por tradición demográfica el recuento de ciudadanos y esclareciendo por nacionalidades a los extranjeros -no por etnias o razas. Los debates y la inclusión fueron seguidos y considerados de manera disímil en los dos países, pero el ansia por marcar a los inmigrantes se hizo patente una vez que los mismos adquirian la nacionalidad del país receptor; apenas con la existencia de una segunda generación de inmigrantes -inmigrados ya nacidos en territorio nacional y con plenos derechos nacionales. Los sujetos pertenecientes a esta segunda y hasta tercera generación de inmigrantes ya no podían ser enumerados en los censos nacionales como foráneos, como extranjeros, sino como nacionales. Por lo tanto, el giro censal-estadístico fue hacia la etnicidad, como elemento diferenciador dentro de las poblaciones europeas. Las etnias tenían una significación diferente a la raza, permaneciendo ajenas a jerarquías, explotación, colonialismo y toda la carga negativa de la categoría antecesora. La etnicidad es nuevamente una categoría que organiza la diferencia, pero que lo hace desarrollando su carga discursiva en el entramado cultural, intencionalmente no basado en esencialismos, que portan distintos grupos humanos para reconocerse y especificar a los demás. Desarticulando la raza de los censos e integrados en un sistema cultural global, un proceso conocido como globalización, ¿cómo quedaría registrada entonces la diferencia? ¿Cómo establecerla? ¿Cómo hacerla viable numéricamente en los censos de población? ¿Es acaso recomendable seguir haciendo esto?

Lo cierto, para empezar, es que muchos países siguieron articulando la diferencia entre grupos poblacionales a través de la raza. Estados Unidos prosiguió con una tradición racial en sus censos (Nobles, 2000; Rodríguez, 2000) y algunos países del Tercer Mundo emularon la fórmula de sus colonizadores para tratar a sus poblaciones estructurando censos racialmente exclusivistas (véase la introducción de Kertzer y Arel, 2002). No obstante estos ejemplos, nuevas categorías de análisis y de uso demográfico empezaron a cobrar relevancia. Pero, en términos antropológicos ligados a categorías censales, se reconsideró 
nuevamente el criterio de etnicidad como concepto analítico que podía ser diferenciado de las connotaciones negativas de la raza. No obstante, lo que desvela su utilización sociodemográfica justo cuando los inmigrantes ya no son, en términos formales, propiamente inmigrantes, es precisamente su sentido racial, la manía excluyente de querer seguir demarcando y estableciendo diferencias una vez se han agotado los medios legales y censales para hacerlo. Por lo tanto, la etnicidad es una garantía, no sólo de considerar diferente al Otro, sino de reafirmar una identidad local: una idea de la Nación que siquiera en tiempos posmodernos bebe de las más viejas fórmulas de tradición, sangre y cultura.

Pero, si la lógica nos dice que la etnicidad entra en el censo para seguir discerniendo a la población una vez empieza a presentarse una segunda generación de inmigrantes ¿qué ha pasado entonces en España? ¿Por qué no se ha visibilizado un debate? En tal caso, ¿existe una demanda para introducir categorías étnicas? Veamos primero, aunque brevemente, dos historias donde esta lógica ha tenido resultados diferentes.

\section{EtNicidad en el CEnso: los casos de Gran Bretaña y FRANCIA}

Por supuesto, estoy presentando un contexto sin matizaciones ni problematizaciones, pero soy bastante consciente de que cada temática que he rozado contiene historias encapsuladas y problemas que deben ser acotados $y$, así mismo, problematizados. No encuentro otra manera de aproximarme a mi propia respuesta a la pregunta principal de este artículo (a saber, por qué no cuenta etnicidades el censo actual español), que a base de pequeñas disquisiciones sobre colonialismo, diferencia racial, etc. Estos titubeos tendrán mayor significación a medida que me vaya acercando, pero, mientras, es preciso presentar, al menos de manera resumida, y siguiendo sin matizaciones importantes, dos pequeños casos comparativos donde el intento de inclusión de categorías étnicas tuvo distintos resultados.

No sólo por próxima vecindad son Gran Bretaña y Francia dos casos comparativos significativos para estudiar la etnicidad y los censos; la ausencia y presencia étnica en el contexto europeo. Genealógicamente fueron las dos potencias imperiales modernas (siglos XVIII y XIX) que 
más influyeron, y lo hicieron en dos sentidos planteados aquí: en la organización estadística del Estado y la investigación antropológica de los Otros. Ambos países conformaron fuerzas paradigmáticas de la contención de la diferencia que en algunos casos coincidian y en otros no. Por lo tanto, sus prácticas multiculturales difieren en el presente. En Gran Bretaña la etnicidad ha pasado a formar parte de la información censal, mientras que en Francia una resistencia amparada en su tradición cívica no ha permitido tal inclusión. En ese sentido, Francia supone el espejo censal donde se mira España, y Gran Bretaña, su opuesto; el anverso de sus prácticas.

Para Arel y Kertzer (2002) Gran Bretaña es un buen ejemplo de confusión entre raza y etnicidad en sus censos nacionales, desde la primera vez que se intentó presentar etnicidades en su propio marco-territorial como categorías estadísticas. Los distintos Race Relations Act, que recorrieron los cincuenta y sesenta hasta culminar con el de 1976, y recientemente reemplazados por el Equiality Act de 2010, unían desde sus comienzos ciudadanía (nacionalidad), etnicidad y raza en un mismo plano discriminatorio: un tipo de enlace que llegó confusamente a las categorías étnicas introducidas en 1991. El censo nacional y sus categorías, reformulaciones de categorías raciales, suponian un claro reflejo de esta confusión de términos en cuanto a usos sociales y políticos. La categoría "Blanco", por ejemplo, recayó en multitud de debates en cuanto a usos apropiados; la categoría "West Indian" (Indio Occidental) también recreó confusión y rechazo por igual, al entrar el censo en un debate crucial, que en aspectos más generales era puesto en cuestión brillantemente por Paul Gilroy (1993) a principios de los años noventa, acerca de la adquisición de una identidad nacional (y una nacionalidad en términos formales y legales) británica por parte de los grupos inmigrantes de segunda generación.

Tras una objeción de los llamados grupos minoritarios, el censo de 1981 no presentó ninguna pregunta de motivo étnico-racial. Una petición de éxito parcial, ya que las autoridades censales lograron ajustar el cuestionario en 1991, introduciendo una amalgama de categorías raciales y étnicas: Blanco, Negro (Negro Caribeño, Africano, Otros), Indio, Pakistaní, Bangladeshí, Chino y Otro origen étnico (Brolcháin, citado en Kertzer y Arel, 2002: 14) ${ }^{5}$.

\footnotetext{
${ }^{5}$ Para ver un recorrido por la inclusión o desestimación de las distintas categorías de nacionalidad, lugar de origen, raza o etnia, véase: Howard, 2004: 106-108.
} 
La introducción de estas categorias en 1991 daría lugar a la publicación de una serie de estudios recopilados en tres volúmenes por la oficina de Estadística Nacional, que estuvieron enfocados en el tratamiento de los datos recogidos en materia de etnicidad (Peach, 1996; Ratcliffe, 1996). Según explica Ceri Peach, geógrafo licenciado en Oxford y encargado del volumen dos, Ethnicity in the 1991 Census Vol. II. (1996), existe un debate nacional polarizado en dos escuelas de pensamiento. Por un lado, se encuentra un grupo que argumenta que puesto que las personas son iguales ante la Ley, las preguntas censales acerca de la etnia, es decir, identidades socialmente construidas para describir la población, sirven para fomentar divisiones. Este sector opina que no debería ser recabada información censal en este sentido. Por otro lado, se argumenta que la desigualdad y la diferencia de trato existen en el país, en términos étnicos, y que por tanto hasta que el problema no sea resuelto se debería cuantificar la etnicidad y fijar así objetivos para la corrección política de la discriminación. Tras las reflexiones de este volumen, se muestra la tabla-cuestionario usada en el censo de 1991. Se presentan así 35 códigos (pre-codificados), condensados en 10 categorías "puras" (Blanco, Negro-caribeño, etc.) más dos categorías "Otros": Otro-asiático y Otro-otro, que según se argumenta contiene diferentes problemas metodológicos a la hora de su aplicación. No se presenta un rodeo histórico, ni tan siquiera una contextualización sociopolítica, tan sólo se comentan algunas cuestiones de definición y se sitúa dentro del debate polarizado. Pero no existe una reflexión acerca de cómo el censo explora e interactúa con la realidad multicultural del país.

La necesidad de incorporar tales categorias tiene que ver con una segunda y hasta tercera generación de inmigrantes. Una generación que pertenece al cuerpo de la Nación, pero que comporta, según el criterio gubernamental y social, unos significantes de diferencia cultural y étnica. Aunque se arguye que el censo pretende escapar a ese dilema poscolonial, en realidad parece suficientemente detonante como para admitir categorías étnicas a pesar de equivalencia ciudadana. Por esa misma razón se complica la relación entre etnicidad y lugar de origen, asignando para el componente étnico un lugar geográfico específico (Pakistaní o Africano Caribeño), resaltando un espaciamiento geográfico-territorial determinado. Para explicar este controvertido punto, los autores de los volúmenes especifican que la etnicidad se une 
con el pasado; con las memorias de un pasado compartido; pero también incidiendo en que no hay cambios estáticos; nada queda enteramente fijado; no hay una verdad absoluta en la definición étnica de la población (Ratcliffe, 1996, vol. 3). Llegamos por tanto a la conclusión de que la "etnicidad es más una categoría situacional que independiente" (Peach, 1996: 5). Sobre esta base ¿qué utilidad tiene recolectar datos censales sobre grupos étnicos para estos autores? En primer lugar: para los analistas políticos, los grupos de presión, etc. Para mejorar en términos pragmáticos las políticas que se auspicien bajo el Race Relations Act. En segundo lugar, para mejorar una categoría como "lugar de origen" tras la confusión generacional. Por ello, las diferencias étnicas se convierten en complicaciones culturales con reminiscencias raciales $^{6}$. El problema ya no es la cuestión de contar inmigrantes admitidos como coloniales, ni de responder a sus intrincadas historias. La introducción de la etnicidad en el censo nacional británico se basa en una superación del debate sobre el trato y el racismo hacia los inmigrantes y se ha enmarcado en una situación sociopolítica más complicada: la del debate por la nacionalidad y la "verdadera" identidad británica en una era de multiculturalismo en decadencia. Un asunto que quiere seguir marcando diferencias esenciales en un ámbito poscolonial, declarado por motivos pragmáticos.

El caso de Francia se presenta con notables diferencias, donde la etnicidad nunca pasó a formar parte de los censos oficiales. No obstante, desde mediados de los años ochenta el fenómeno de la inmigración ha estado generando un debate acerca de la posible inclusión de categorías étnicas que tenía vistas de hacerse efectivas en el censo de 1999. Toda esta cuestión no viene sin liturgia política, en la cual una notable maquinaria de diferenciación para marcar a nuevas

\footnotetext{
${ }^{6}$ Por presentar el estado de la cuestión en la reflexión de Ratcliffe, responsable del tercer volumen: Es inconcebible que la categoría "Blanco" puede ser considerara bona fide un grupo étnico, conteniendo, tal como lo hace, todas los grupos nacionales de las Islas Británicas, todas las naciones europeas (incluyendo a grupos sureuropeos como los chipriotas tanto de origen griego como turco), norteamericanos, surafricanos y australianos de origen europeos. "Negro-Caribeño" subsume todos los grupos del archipiélago sin importar que sean de origen anglófono o francófono: Negro-Africanos, todos los residentes del África subsahariana que son por herencia "no-Blancos". Cada uno de los grupos comprendidos dentro de la categoría Sur-Asiático es altamente diverso internamente, incorporando a hindús, musulmanes, sikhs, gujeratis, kashimires, tamiles y tantos otros grupos. Los comprendidos en "Chino" son igualmente diversos (con muchos sub-grupos nacionales, regionales, lingüísticos y religiosos) (Ratcliffe, 2008: 12).
} 
generaciones de inmigrantes asentados en Francia estaría tambaleando una tradición censal, intimamente relacionada con su identidad republicana, su marco constitucional y la posición que han tomado las estadísticas de este país con respecto a la arena internacional ${ }^{7}$. Alain Blum (2002) ha sido bastante perspicaz al poner en perspectiva este debate francés ${ }^{8}$.

"[L]a posición francesa ha sido la de distinguir con (...) claridad entre los ciudadanos franceses y los extranjeros. Los primeros son vistos como constituyentes de una única y singular nación. Para los extranjeros se ha tratado de encajarlos en una categoría fija, clara y jurídicamente precisa: una categoría nacional" (Blum, 2002: 129).

Solamente esta fórmula era aceptada, auspiciada por la definición de ciudadanía de 1889 (basada en el derecho de ius solis) y un concepto de estado cívico 9 .

Pero siquiera siendo ésta una tradición estable, que unía conceptos cívicos con tradición censal, esta concepción no se aplicaba al imperio colonial. Blum toma el ejemplo de Argelia para apreciar cómo era operativo un escrutinio racial de la población, fragmentando la sociedad colonial entre un ente musulmán (étnico-religioso) y otro europeo (inicialmente francés, pero que con el tiempo comprendería otros países). Los miedos a la formación racial argelina, imbuyendo tanto a indígenas como colonos en un proyecto común de secesión, despertó en el gobierno francés la necesidad de intensificar aún más la diferenciación en la colonia entre colonos e indígenas, procurando así nacionalidad en función de una especie de etnicidad o raíz francesa. El censo colonial vino a reflejar estas operacionalizaciones dando lugar a tres categorías que escaparian el hasta ahora constante espectro dicotómico francés: franceses, franceses crémieux (de mezcla) e indígenas (Blum, 2002: 136).

\footnotetext{
${ }^{7}$ Pero también daría como resultado, a ciertos extremos del espectro político nacional, el revivir de nociones raciales tradicionales evidenciadas en las de "Galo" o aquellas de "raíz francesa" ("Français de souche") como marcaciones étnicas de un ente ciudadano francés. ${ }^{8}$ Para este apartado también utilizo las revisiones de Cohen $(2002 ; 2003)$.

${ }^{9}$ Por lo tanto los cuestionarios han reflejado categorías cerradas y rígidas con respecto a la otredad que se contenían en territorio nacional, como por ejemplo: "nacidos de padres franceses", "naturalizado francés", "extranjero, de qué país" en 1896, siguiendo cambios regulares, pero no disruptivos hasta 1962, cuando fue introducida una pregunta suplementaria acerca del país original, dirigida a los naturalizados franceses.
} 
Tras el periodo colonial, el debate de la inmigración tuvo un momento crucial con respecto a las categorías de recuento en censos. Seguiré las notas de Blum (2002) y Cohen $(2002 ; 2003)$ para presentar el debate y sus críticas. En 1992 se llevó a cabo una encuesta acerca de ciertos aspectos de los inmigrantes titulada "Movilidad Geográfica e Integración Social" (MGIS), insólita en Francia pese a que ya se habian realizado algunos registros estadísticos que contemplaban criterios de etnicidad (al menos de tipificaciones de diferencia). La encuesta fue llevada a cabo por la INSEE (Instituto Nacional de Estadística Económica, en su acrónimo francés) y por la INED (Instituto Nacional de Estudios Demográficos). Fue presentada en el año 1993 y sus resultados fueron publicados en 1995 en Faire France.

Se presentó así una clasificación que discernía entre los franceses de ascendencia francesa y los de padres inmigrantes, "rompiendo la tradicional distinción entre ciudadanos franceses y extranjeros (...) el objetivo era realizar un estudio de la inmigración y su futuro, de los inmigrantes y sus descendientes y no de la nacionalidad de la población" (Blum, 2002: 38).

Varios estallidos de violencia (étnica) en barrios marginales de París a principios de la década y diversas cuestiones relacionadas con la exclusión en las escuelas y la discriminación en el trabajo y la vivienda expandieron el debate a los medios y la opinión pública.

Cinco puntos críticos fueron expuestos contra las categorías étnicas (y su uso) en el MGIS: 1. El reconvertir científicamente expresiones populares de pertenencia nacional como "Français de souche" y la utilización política que la extrema derecha podría hacer de esa reconversión. 2. Las reminiscencias coloniales en la definición actual, ya que se discernía entre categorias nacionales adscriticas a residentes de países europeos y nociones étnicas o no-nacionales para referirse a inmigrantes del norte de África y Turquía, así como a aquellos provenientes del África sub-sahariana. 3. La centralidad del origen en la conceptualización de la etnicidad, basada no en la biografía de los/as inmigrantes, reduciendo bastante la capacidad más flexible y las otras variables que tiene la misma etnicidad. 4. Los usos generales del estudio; la unión entre la esfera política y la demografía, especialmente, también, por el provecho político que podía sacarle la extrema derecha. 5. Por último, la cuestión de la privacidad y los usos de la información, una polémica que viene acompañada por el descubrimiento de un 
documento sobre los judíos franceses recopilado por el régimen de Vichy durante la Segunda Guerra Mundial, y estrechamente ligado al servicio de estadísticas nacionales y al censo.

Arón Cohen Amselem (2002) esbozó perfectamente los puntos en que la encuesta y sus casillas establecian la diferencia colonial, separando nuevamente un ente nacional de los Otros-inmigrantes:

\begin{abstract}
"Origen étnico" y "pertenencia étnica" son categorías imputadas a los encuestados por la responsable de la investigación [Michele Tribalat]. La segunda, de un modo doblemente selectivo. Se aplica sólo a los originarios (...) de países en los que se hablan distintas lenguas. Pero no a todos los que entrarían en esta situación: sólo a los del Magreb y, en general, a los africanos, además de a los de Turquía; no, por cierto, a los españoles, como tampoco a los "franceses de cepa" a los que sigue haciéndose referencia y en los que se revela una "consecuencia técnica" cosificada de otro a priori de la encuesta. "Árabes" y "bereberes" de Argelia y de Marruecos (separadamente); "turcos" y "kurdos" de Turquía; y, por otra parte, grandes reagregaciones ad hoc en lo que respecta a los orígenes africanos al Sur del Sáhara ("mandés de África Negra"; "wolofs y peuhls de África Negra")." (Cohen, 2002: 218. Cursivas en el original).
\end{abstract}

La respuesta de los organismos a estas aéreas de criticismo serían: el desmarque de la afinidad política con la extrema derecha y la reafirmación en un procedimiento investigador a-político; la comparación con otros países que sí usan información de este tipo (especialmente con el mundo anglosajón); y la necesidad de combatir con más brío la discriminación generada con el fenómeno migratorio. No obstante esta nueva ruptura, la tradición censal basada en el estado cívico pesó más que la tentativa de insertar categorías étnicas en el censo nacional, un asunto que ha pasado por la gestión administrativa del gobierno de Nicolás Sarkozy, favorable a la clasificación étnica del censo electoral.

\title{
4. El CAMINO de (LAS) España(s)
}

En estos dos países la inmigración ha condicionado directamente la tradición censal anterior (o al menos la ha pretendido alterar); una tradición nacional ampliamente dividida con respecto del mundo colonial de los respectivos imperios, lo que les permitía en calidad de potencias y de naciones (de Nación en cuanto que narrativa propia de un 
determinado estado territorial) establecer diferencias mientras aseguraban una noción estable de ciudadanía. Pero ¿qué estrategia política y gubernamental estaba en juego con estos cambios? ¿Se trata, como indican los volúmenes oficiales de Gran Bretaña, de un debate polarizado, que en su polo positivo intenta aproximarse mejor al problema de la discriminación en relación al aumento de sujetos inmigrantes en territorio nacional? Ese viene siendo el mismo argumento de los organismos estadísticos franceses encargados de llevar a cabo la encuesta MGIS (con proyección de modificar el censo de 1999), y una de sus respuestas a las críticas más amargas. ¿Se trata de estudiar en condiciones la diversidad étnica floreciente en Europa con las migraciones poscoloniales o de ejercer de panóptico para supervisar y controlar a la población con un tipo de ordenamiento propiamente colonial? En otras palabras: “¿Distinguir y caracterizar poblaciones en función de sus orígenes étnicos constituye un riesgo de estigmatización o es, al contrario, un imperativo para medir y explicar la discriminación y demandar políticas más inclusivas?" (Simon y Piché, 2011: 1358).

Estas cuestiones rondan incómodamente alrededor del futuro de la demografía misma, en un mundo global novedoso pero difícilmente disociado del pasado colonial y de la mala conciencia poscolonial (o la melancolía) que achaca a las políticas públicas en la Europa de hoy.

Por ahora, ya expuestos los dos ejemplos de debate al respecto, intentaré dar algunas aproximaciones de esta problemática (que no existe en forma de debate en España), a la idea de un censo libre de categorías étnicas: ¿Por qué esa resistencia española? Aun sin la existencia de un debate público y amparado por una tradición censal pionera en Europa, cabe preguntarse por esta ausencia en un país como España considerando al menos tres razones.

En primer lugar, existe una fijación por el recuento estadístico de la inmigración, convirtiéndose en un poderoso ensamble de un discurso para establecer la diferencia a base de clichés culturales (véase Santamaría, 2002). Permítanme presentar este primer punto con unas palabras de Arón Cohen Amselem, que expresa certeramente que

"Los argumentos cifrados, vale decir demográficos (aunque muchas veces lo sean sólo de un modo espontáneo y formal), han venido siendo elementos destacados en la construcción en España, a lo largo de decenio y medio, de un discurso muy habitual sobre la inmigración de ciudadanos extranjeros. 
Obvio es decir que este rasgo característico desborda con creces el ámbito de los muy numerosos trabajos de especialistas en la amplia gama de ciencias sociales que se han interesado por el fenómeno de la inmigración. Hasta el punto de que no pocas veces los análisis estadísticos han entrado en contradicción con clichés mediáticos y políticos, que son, por otra parte, suficientemente poderosos, para no haber carecido de eco académico" (Cohen, 2002: 213. Cursivas en el original).

Esta obsesión demográfica-numérica, que se entronca con una inestable combinación de medios de comunicación y sociología, expresa un anhelo de marcar al inmigrante en un discurso que matiza las diferencias entre lo local y foráneo. Estos "argumentos cifrados" que componen una parte sustancial del discurso de la inmigración, son viables cuando los inmigrantes no pertenecen al cuerpo de la Nación ${ }^{10}$, pero hay que recordar que su presencia se expande en el tiempo, imposibilitando un seguimiento censal de lo que la Nación considera "diferente". Según la normativa, es posible para los inmigrantes solicitar la nacionalidad habiendo demostrado diez años de residencia en España, de manera legal y continuada. Existen no obstante excepciones: descendientes de españoles, los refugiados políticos (que necesitan cinco años de residencia continuada); y dos años para aquellos provenientes de Hispanoamérica (países con vinculación histórica con España), Andorra, Guinea Ecuatorial, Filipinas, Portugal y los judios Sefardies.

La segunda cuestión, que nos aleja de un marco cívico, viene de una tradición censal que cuenta con censos coloniales (como antes expliqué) para especificar ese núcleo diferencial en su propia genealogía. Por lo tanto, no nos puede sorprender el volver a marcar, en España, usando variables étnicas o raciales para especificar población(es); la única gran diferencia es que mientras antes se usaban alli, ahora se usarían aquí. Por último, un tercer punto que puede ser el que ofrezca la resistencia más sólida a ese posible escenario en el censo nacional. La propia diferencia interna de la Nación española ha querido verse, desde la óptica del Estado (central) como una diferencia asimilable, que-cabe-enun-todo. La España de las comunidades autónomas fue la organización

\footnotetext{
${ }^{10}$ Como dice Cohen: "La problemática inmediata de los análisis cuantitativos de la inmigración en España se ha suscitado en lo esencial, salvo excepción, dentro de los límites de la variable extranjería" (Cohen, 2002: 219).
} 
política-territorial de unas diferencias internas que con el franquismo habian sido duramente reprimidas. Las críticas y las reflexiones intelectuales abundan acerca del tour de force del Estado-nación español con respecto a la contención de la diferencia en este marco territorial-administrativo.

En este sentido, contener la diferencia se ha convertido en algo imposible, un punto en el cual se enfrentan también ambos polos políticos mayoritarios en España, pasando a definir el vanguardismo (o el conservadurismo) según la calidad de la gestión de esa diferencia, aunque lo cierto es que esta cuestión sacude y aturde al espectro político asentado en el gobierno central, al tiempo que refuerza la "normalidad" (Delgado, 2009). Lo que sí ha podido hacer el nacionalismo español adscrito al circuito estatal es negar la diferencia como estatus administrativo, como un dato de validez científica $y$, en definitiva, construir una Nación reforzando puntos comunes, o imponiéndolos, según criterios. Lo que siempre primo en el debate político fue un titubeo entre la definición que el espectro entero daba con respecto a la nación y la nacionalidad, jamás entendidas como construcciones de otredad o una narrativa de la Nación. De esta manera, en España ocurre una doble negación: por un lado, como vengo exponiendo, la negación de varias etnicidades comprendidas como tal dentro de un marco administrativo-territorial. Por otro, la negación de una propia etnicidad española. Parafraseando a Stuart Hall (1991): admitir que los españoles constituyen una etnia, tal como lo son otros grupos humanos, con sus límites, y una confrontación con un Otro determinado, "flotando al filo de Europa, con su propio lenguaje, sus propias costumbres particulares, ritos y mitos...". Este nivel de negación es circunvalado por las aguas coloniales, es una negatividad que pertenece, como explica Hall (1991; 1992), a Europa. Como indica Christiane Stallaert: "en plena era de etnicidad, la española, como objeto de estudio, yace en barbecho, o lo que es peor, intocable" (Stallaert, 1998: 7. Cursivas añadidas). Por lo tanto, se produce una contradicción externa:

"Respecto de la cuestión étnica nos encontramos hoy día en la Antropología española con una situación bastante contradictoria. Mientras que por un lado se niega toda homogeneidad de la población del país, esta misma homogeneidad es admitida e incluso reivindicada para las distintas regiones (o "pueblos"), de modo que los estudios 
sobre la etnicidad sólo parecen justificados a nivel infraestatal" (Stallaert, 1998: 16).

\title{
5. ¿RESALTAR LA DIFERENCIA SIN INVOCAR LA ETNICIDAD?
}

Para los demógrafos, todavía estamos en un periodo de buenas prácticas, de conceptos manejables y aptos. Sí, es también un estado donde existe mucha contaminación política y por parte de medios de comunicación sobre las categorías y los datos estadísticos, pero de los que no desfasa, anacrónicamente a ese progresivo arranque, a usar categorías fuera de su alcance. Unas taxonomías por otro lado olvidadas, relegadas al pasado colonial. No obstante, cuando se lanza una mirada al futuro por parte de los demógrafos, es como si ese viejo mundo se nos viniera nuevamente encima. Sin ni siquiera haberse presentado como poscolonial, España está tentando los destinos de los países con migración poscolonial, y su sorpresa ante ello, ante el aumento de inmigrantes extra-comunitarios podríamos decir, le viene por el marcador poscolonial temporal, que de alguna manera debe haber interiorizado. En otras palabras, la sensibilidad moral que aflora con el debate de la incorporación de categorías étnicas en el terreno censal se mantiene sólo en latencia.

Brancós, Domingo (2000) y Cohen (2002), a principio de la década de los dos mil, auguraban que las categorías étnicas entrarían a formar parte de la demografía española. Lo hacían mirando a Francia como modelo referencial:

\begin{abstract}
“¿Hay que esperarse más o menos pronto entre nosotros algún tipo de tentativa ( $y$ de desencuentro) a la francesa? Recuérdese que nuestro Código Civil (Libro $1^{\circ}$, Título $1^{\circ}$ ) incluye entre los titulares de la nacionalidad española "de origen" (art. 17) a los hijos de matrimonios mixtos y a los que entran en el caso de "doble ius soli", es decir "nacidos en España de padres extranjeros si, al menos, uno de ellos hubiera nacido también en España" (...) Por supuesto, no habría que perder de vista las posibles reformas de la ley, como la que actualmente completa su trámite parlamentario en materia de "recuperaciones" de la nacionalidad española por parte de "emigrantes" y sus descendientes, otro "origen" de potenciales disquisiciones" (Cohen, 2002: 220. Cursivas en el original).
\end{abstract}

El camino que está siguiendo España es ciertamente similar al francés. Pese a que el porcentaje de inmigrantes no sea tan alto como el de las 
vecinas Gran Bretaña y Francia, es obvio, no obstante, que el eco mediático lo ha magnificado, haciendo de la intervención política al menos deseable en términos sociales. Además, en clara relación, una segunda generación de hijos de inmigrantes empieza a ser una realidad ("visible"). Yo ahora me pregunto: ¿pueden ser el censo de 1991, junto con los posteriores, y la Encuesta Nacional de Inmigrantes, realizada por primera vez en 2007, antecedentes genealógicos en la constitución de categorías étnicas para el recuento censal? Cohen (2002) a través de un trabajo de Patrick Simon, contempla como los conceptos manejados en demografía fueron procreados institucionalmente en Francia; primero, en los ochenta, como indicadores complementarios para otra categoría demográfica (jóvenes), para luego ocupar una significación por sí sola en los años noventa con la encuesta MGIS. Trasladado al caso español, Cohen anota lo siguiente:

\begin{abstract}
"Baste pensar, por ejemplo, en el diferencialismo de hecho, entre extranjeros de distintos orígenes geográficos, revelado (a veces explícitamente) por algunas prácticas patronales de empleo aireadas por los medios de comunicación; o en la visibilidad conferida, en plena estela de los acontecimientos del 11-S, a ciertos rasgos de la composición de las tropas españolas basadas en las ciudades de Ceuta y Melilla (EI País, $31 / 10 / 01)$; por no hablar de la logorrea culturalista en torno al chador. Pero tampoco hay que olvidar las encuestas de opinión que se fijan en las percepciones de la inmigración, a menudo cargadas de buenas intenciones, y que preguntan algunas veces con categorías que oscilan entre nacionalidades de inmigrantes y minorias de perfiles imprecisos, diluyendo con ello la referencia al suceso migratorio o, mejor dicho, convirtiendo de hecho la condición de inmigrante en atributo indeleble $y$ de transmisión hereditaria. También, efectivamente, en nombre de ciertas acepciones del respeto a la diferencia, quizás a veces (implícitamente) por déficit de laicidad, podemos toparnos con muy antiguos demonios taxonómicos" (Cohen, 2002: 220. Cursivas en el original).
\end{abstract}

Esto es una manera tímida de ir re-introduciendo la diferencia en el orden estatal-administrativo, pasando a codificar ramas enteras dentro de la información socio-estadística disponible por y para el Estadonación. Sin embargo, su pasado es más complejo y, en cierto sentido, menos tímido. 
Creo haber recorrido algunos rincones oscuros de la incursión española en África, un lugar donde se refinó la maquinaría de marcación. Si suponemos que esa etapa tiene un fin ilusorio y no un fin efectivo, se nos hace posible entender, pues, el ansia de establecer diferencias. La genealogía tiene aquí unos giros más escurridizos por diferentes historias de movilidades y fijación de los espacios. España siempre ha discernido a sus Otros, hasta ahora, en un marco administrativoterritorial considerado español, pero siempre prefigurando un apelativo colonial. Lo ha hecho usando diversas taxonomías étnico-raciales en clara interconexión con otras disciplinas y motivados por sendos contextos geopolíticos. Cuando se proyecta un futuro escenario mirando a Francia se hace sólo contemplando una política de nacionalidad (de admisión) similar y un modelo censal libre de etnicidad; en la tradición cívica se podría decir, que se comparte a ambos lados de Los Pirineos. Se fijan en la estadística, pero no en la historia y la geopolítica; olvidan observar las idiosincrasias de la organización de la diferencia interna y la noción de raza (principal elemento diferenciador bajo el imperialismo) que España presentaba en su discurso colonial, articulada precisamente en contraposición a Francia y las otras grandes potencias imperiales de los siglos XIX y XX. ¿Es de suponer entonces otro escenario?

Tanto Cohen como Brancós y Domingo no son del todo ajenos a estas consideraciones genealógicas. En una nota al pie de página ligeramente ampliada en su artículo de 2003 con respecto a una ponencia dada el año anterior, Cohen dice en relación a volver a usar taxonomías problemáticas relacionadas con la etnicidad, que "También en España contamos con el precedente de una práctica colonial en el siglo XX. Las distinciones étnico-religiosas en la estadística del Protectorado español en Marruecos son un reflejo tardío de criterios arraigados en el 'africanismo' etnológico, de indudable influencia... francesa" (Cohen, 2003: 13 , nota al pie $\left.n^{\circ} 15\right)$. El autor quiere seguir estableciendo paralelismos entre países, desterrando accidentalmente otras variables. No obstante, es lo bastante perspicaz para darse cuenta de este antecedente, siquiera reduciéndolo a una nota al pie. Pero, cuando el autor se refería a "muy antiguos demonios taxonómicos", una reflexión que da pie a su nota, ¿a qué mucha antigüedad se refiere? ¿Hasta dónde llega la genealogía en este caso? Brancós y Domingo (2000) llegaban hasta la clasificación de "cristianos viejos" lo cual parece un disparate. 
Pero es de notar algo muy específico de sus conclusiones y reflexiones sobre el asunto, no tanto de esta retrospectiva al pasado en busca de antecedentes (algo que tiene en cuenta Domingo, el pasado colonial, al ver su influencia en la presencia africana en España: véase Domingo y Vono, 2013), sino en las problemáticas de codificar la inmigración bajo el manto del "Origen".

\begin{abstract}
"Nada hemos dicho hasta el momento, sobre el conjunto de personas inmigradas (extranjeras más nacionalizadas), o sobre su descendencia (la llamada "Segunda generación" (a las que se pueden añadir los ordinales que se quiera), tampoco hemos considerado la etnicidad como característica susceptible de determinar una población, y por tanto de analizarla desde el punto de vista demográfico. No lo hemos hecho aquí porque nos preocupa, y porque introduce necesariamente consideraciones que se escapan a las dimensiones de las presentes reflexiones. Somos perfectamente conscientes, sin embargo, que en un futuro inmediato ese problema metodológico va a tener que abordarse desde la demografía y en nuestro país: somos conscientes de que ya existe una demanda para ello. Queremos advertir sin embargo (...) que el desplazamiento en el análisis de la inmigración al origen o a la etnicidad como característica esencial de la población inmigrada, acaba por anular el fenómeno que se pretendía estudiar: el hecho de haber emigrado. Ese hecho pone de relieve una última cuestión: ¿Hasta cuándo se es migrante? La determinación de poblaciones partiendo de constructos socio-culturales como la etnicidad, abre la puerta a la creación de visibilidad estadística de subpoblaciones con evidentes implicaciones sobre su percepción y sobre lo que se entiende por integración, ese debate excede el campo de la demografía, o es que en nombre del respeto a la diferencia ¿estamos dispuestos a resucitar la castiza clasificación de cristianos (españoles) viejos?" (Brancós y Domingo, 2000: 24. Cursivas añadidas).
\end{abstract}

Anularlo no supone un problema. El objetivo principal de establecer las categorías de etnicidad se revela aquí no como una demanda de mejoramiento del estudio del fenómeno de la inmigración, sino, en sus términos positivos, como una demanda de un tipo de información generada para combatir la discriminación racial, y en su aspecto más negativo, como una demanda de información para forjar una forma de control más eficaz: sí, en términos políticos. Lo cierto de todo es que posibilita seguir diferenciando a la población una vez que la maquinaría 
estatal para establecerla (tanto en términos demográficos como legales o sociales) se queda corta, cuando ya no puede marcar más dentro de un encuadre paradigmático administrativo... Lo realmente importante es mantener un sentido de lo Otro y, en cierta medida, de Nuestros Otros, pues favorece, entre otros aspectos, la funcionalidad económica y cultural del Estado-nación y su marco de integración basado en afinidades que pretenden seguir siendo étnicas (Gil Araújo, 2010) en el capitalismo tardío. Si excede o no a la demografía no depende de que la visibilidad étnica y sus correlatos de discriminación (ya sean en términos positivos o negativos) pertenezcan a otro ámbito disciplinar, sino a que la contención y definición de esas "subpoblaciones" no puede hacerse efectiva sin ella.

El censo vuelve aquí a ocupar su lugar central como nodo que articula la diferencia en torno al fenómeno migratorio; es el lugar al que aspira todo dato, toda información, convirtiéndose en un componente importante en el discurso de la inmigración. Basándose en ideas de Theodore Porter, Donna Haraway escribe: "la estadística es una tecnología básica para la creación de objetividad y la estabilización de los hechos (...) La impersonalidad de la estadística es uno de los aspectos de la compleja intersubjetividad de la objetividad; es decir, de la calidad pública del conocimiento científico" (2004: 230). En este sentido, las estadísticas funcionan como un tipo de comunicabilidad para grupos a larga distancia (y pongamos como ejemplo, una Nación), que creen más en el carácter experto, propiamente objetivo de la realidad numérica, que en la comunidad en sí (Porter en Haraway, 2004: 230; Porter, 1996). Ganarse esa confianza depende de ese carácter del censo, que tiene ese poder para ir más allá de su estado zombi. Nada excede en este sentido a la demografía, pues si la etnicidad debe o quiere establecerse como realidad objetiva, como un dato más que puede ser cuantificable y por tanto analizable y reconducible a otras disciplinas, debe pasar por el "esterilizado" terreno censal. Algo que ya se ha hecho en el periodo colonial. Y esto es así tanto en términos pragmáticos positivos o negativos.

Pero, ante esa "demanda", ¿cómo contiene el censo una posible articulación entre la diferencia étnica nacional y la extra-nacional? La resistencia española ofrece una contra, expresada, por ejemplo, en el 
artículo de El País en 2009, con respecto a la utilización de estadísticas étnicas en Francia ${ }^{11}$ :
"Ana Jurado, subdirectora general del Instituto Nacional de Estadística español, recoge el guante: "No nos ocurrirá eso [una polémica por el uso de categorías étnicas en las estadísticas]. España cuenta con un sistema de padrón del que Francia carece. Este sistema nos permitirá, si es

\begin{abstract}
${ }^{11}$ Por tener un censo desprovisto de etnicidades y un marco cívico del mismo, Francia se ha convertido, como ya dije, en el espejo donde se mira el censo español. Esto es compartido tanto por el artículo de prensa nombrado en este apartado como por demógrafos y sociólogos. Francia aparece siempre en el horizonte: "¿Hay que esperarse más o menos pronto entre nosotros algún tipo de tentativa (y de desencuentro) a la francesa?" decía Cohen al respecto (2002: 220, cursivas en el original). Pero si tenemos en cuenta la contención latente con respecto a la diferencia interna en la Nación española quizás un mejor "espejo" pueda ser el caso británico, a su vez espejo donde se mira la demografía francesa. Esto es así porque existen diferencias internas que pugnan por autogobierno y reconocimiento. Estar reflejadas por el censo nacional como etnicidades podría ser una concesión o un reconocimiento de tales diferencias que el gobierno central intenta negar en pos de la unificación nacional. Por lo tanto, cuando en 1991 se introdujeron por primera vez en Gran Bretaña, se obviaron las categorías étnicas de escoses, gales e irlandés. La cuestión tampoco vino sin liturgia política. Al negar esas clasificaciones para el recuento censal, la etnicidad supuestamente autóctona de Gran Bretaña pasó a codificarse en un tono más racial y generalizante, tal cual lo venía siendo, también, todo su cuadro. Así, "White British" (Blanco Británico), una categoría más racial que étnica, pasó a ocupar el espacio étnico de todas las diferencias dentro de la Nación, haciendo efectiva las diferencias entre las razas o etnias "típicamente" foráneas y, otro bloque, contado en la misma dimensión, en el mismo encuadre, como local. La liturgia se hizo obvia en un punto: cuando distintos grupos de presión periféricos pidieron reconocimiento estadístico, esto es, que sus etnicidades fueran enumeradas y consideradas tal cual lo eran las otras. Detrás de esto, por supuesto, estaba la cuestión del color de la piel, uno de los marcadores más eficaces de la raza. Diversas asociaciones civiles, de las que cabe destacar Action Group for Irish Youth [AGIY] (Howard, 2004), movilizaron recursos para proponer la inclusión de una categoría "Irish". La respuesta estatal inmediata fue la negación, argumentando que la razón principal de la recolección de datos de carácter étnico obedecía a una necesidad primaria de política antidiscriminatoria y que los irlandeses ya no eran un colectivo en peligro de marginación en los años noventa (algo también dudoso). La inclusión de tal categoría podía suponer, además, "un riesgo...demasiado grande" (Oficina Nacional de Estadisticas en una carta a Seamus Taylor, citado en Howard, 2004: 112-113). El caso de Escocia fue contenido por la cesión de la autoridad censal a través del Scotland Act de 1998, donde el parlamento de Edimburgo pasaría a tener exclusividad del recuento de sus ciudadanos. En el traspaso, la categoría blanco no resultó en una fragmentación de su nomenclatura. Para los ciudadanos galeses; sólo aparecían reflejados en el censo si en la casilla "Otro" del cuestionario censal se especificaban como que galeses. En 2001, después de una década de presión y enfrentamiento, la categoría Irish fue incluida, pero así las cosas, los grupos periféricos de las islas británicas parecen lejos de estar satisfechos. En cualquier caso esto muestra el deseo estatal de visibilizar la diferencia racialmente, a sus ahora-nacionales con cierto color de piel y cierto origen relacionado con un imperio que ya no es (para ver el recorrido entero de esta inclusión véase el interesante trabajo de Kevin Howard, 2004).
\end{abstract}


necesario, seguir los movimientos de los descendientes de los inmigrantes y saber dónde se concentran" (El País, 1/4/2009).

De momento, en España, se ha estrechado temporalmente la posibilidad de codificar étnicamente las estadísticas, pero ya se va mostrando el tic clasificatorio a través de una nueva pregunta censal introducida para el censo de 2011: "Padre o Madre nacida en el extranjero". Los resultados vienen bajo el rótulo "Segunda generación de inmigrantes":

“Del total de personas nacidas en España, 1.364.849 tienen padre nacido en el extranjero y 1.410 .248 madre nacida fuera. En ambos casos, los países de nacimiento más frecuentes de los progenitores son Marruecos (con porcentajes en torno al 20\%) y, a gran distancia, Francia, Rumanía y Ecuador (...) El número de personas nacidas en España con padre y madre nacidos en el extranjero es de 797.289. En el $81,7 \%$ de los casos, el país de nacimiento de los padres es el mismo, siendo Marruecos, Rumanía y Ecuador los países más frecuentes" (INE, 2011, nota de prensa).

La variable extranjería sigue entonces, hasta el momento, siendo operativa (efectiva), conectando a muchos sujetos vía el origen de sus progenitores, pero ¿será el sistema indicado por Ana Jurado, del INE, suficiente para rastrear la diferencia y ser operativo con la discriminación étnica/racial? En cualquier caso, la opción de Jurado implicaría que la inmigración, no la condición étnica, es por definición una herencia biológica ${ }^{12}$, una carga de la cual nunca se podría desentender un sujeto, no importa cuánto se haya asimilado o integrado con la cultura local/nacional, puesto que la marcación étnica se vincularía no sólo con los componentes culturales, sino que haría hincapié, destapando el carácter biopolítico de tal medida, en la condición de inmigrante, en la otredad subyacente a un proyecto de clasificación con reminiscencias coloniales.

La viabilidad de explorar la etnicidad de la Nación queda por tanto suspendida en un vacío, por el cual llegamos a un estado de latencia biopolítica en la que David Boyle está en lo cierto. Su reflexión más intrigante puede servir de referente para la situación en la que se encuentra la Nación; como la de un país en falso: ¿Contar o no contar etnias? "Si no las cuentas, cesan de existir, si las cuentas, se pervierten"

\footnotetext{
${ }^{12}$ Esta reflexión surgió en discusiones privadas en correspondencia con Arón Cohen, al cual estoy muy agradecido.
} 
(Boyle, 2000). Esa es y será la perdurable paradoja con la que convive el censo en España.

\section{BIBLIOGRAFÍA}

Anderson, B., 2006, "El censo, el mapa y el museo", en B. Anderson, Comunidades Imaginadas, Fondo de cultura económica, México, pp. 228-259.

Appadurai, A., 2005, "Number in the colonial imagination", en A. Appadurai, Modernity at Large, University of Minnesota press, Minneapolis, pp. 114-135.

Barth, F., 1969, Los grupos étnicos y sus fronteras. La organización social de las diferencias culturales, Fondo de Cultura Económica, México.

Blum, A., 2002, "Resistance to identity categorization in France", en D. I. Kertzer y D. Arel (Eds.), Census and identity. The politics of race, ethnicity, and language in national census, Cambridge University Press, New York, pp. 121-147.

Brancós, I., Domingo, A., 2000, "Entre el flujo y el stock: el análisis demográfico de las migraciones internacionales y de la población de nacionalidad extranjera en España", Ponencia presentada al IV Congreso de Inmigración Africana: "Las migraciones a debate", celebrado en Almeria, del 6 al 8 de abril de 2000.

Boyle, D., 2000, The Tyranny of Numbers, Harper Collins, London.

Christopher, A.J., 2002, "To define the indefinable: population classification and the census in South Africa", en Area. No. 34, 4. pp. 401-408.

Cohen Amselem, A., 2002, "Las categorías estadísticas de la inmigración: acotaciones a un debate francés", en Laboratorio de Estudios Interculturales (Ed.), La inmigración en España. Contextos y alternativas. Vol. 2, Actas del III Congreso sobre la Inmigración en España (ponencias), Laboratorio de Estudios Interculturales, Granada. pp. 213-222.

Cohen Amselem, A., 2003, "Las categorías estadísticas de la inmigración: acotaciones a un debate francés", en Eria, no. 60, pp. 5-15.

Cornejo Parriego, R. (Ed.), 2007, Memoria colonial e inmigración: la negritud en la España postfranquista, Bellaterra, Barcelona.

Curtis, B., 2001, The politics of population. State Formation, Statistics, and the Census of Canada, 1840-1875, University of Toronto Press, Toronto. 
Delgado, L.E., 2009, "La nación (in)vertebrada y la crisis de la normalidad democrática", en Revista Científica de Información y Comunicación, n. 6, pp. 215-233.

Desrosiéres, A., 2004, La política de los grandes números. Historia de la razón estadística, Melusina, Barcelona.

Domingo, A., Vono, D., 2013, "Africanos en los países de Europa meridional: Italia, España y Portugal", en Notas de población, no. 95, CEPAL (Comisión Económica para América Latina y el Caribe) y CELADE (Centro Latinoamericano y Caribeño de Demografía), Santiago de Chile, pp. 107-146.

Estévez, P., 2012, "Censo, identidad y colonialismo en el Sáhara español (1950 - 1974): la imaginación numérica de la nación española", en Papeles del CEIC, $n^{\circ}$ 89, Disponible en: http://www.identidadcolectiva.es/pdf/89.pdf.

Estévez, P., 2013, "Migraciones y censos. Los dilemas de contar categorías fijas en contextos dislocados", en Atlántida, $n^{\circ} 5$. Disponible en: http://publica.webs.ull.es/publicaciones/volumen/atlantidavolumen-5-2013/.

Gil Araújo, S., 2010, "The Coloniality of Power and Ethnic Affinity in Migration Policy: The Spanish Case", en E. Gutierrez, M. Boatca y S. Costa (Eds.), Decolonizing European Sociology, Transdisciplinary Approaches, Ashgate, Surrey, pp. 179-194.

Gilroy, P., 1993, The Black Atlantic. Modernity and Double Consciousness, Harvard University Press, Cambridge- Massachusetts.

Gilroy, P., 2008, Después del imperio. ¿Melancolía o cultura de la convivialidad? Tusquets, Barcelona.

Hall, S., 1991, "The local and the Global: Globalization and Ethnicity", en A.D. King, (Ed.), Culture Globalization and the World-System. Contemporary Conditions for the Representation of Identity, Macmillan-State University of New York, Binghamton, pp. 19-39.

Hall, S., 1992, "What is this 'Black' in Black popular culture", en M. Wallace y G. Dent (Eds.), Black Popular Culture, Bay press, Seattle, pp. 21-33.

Haraway, D.J., 2004,Testigo_Modesto@Segundo_Milenio.HombreHembra ○_Conoce_OncoratónR: feminismo y tecnociencia, UOC, Barcelona. 
Howard, K., 2004, "Constructing the Irish of Britain: Ethnic recognition and the 2001 UK Censuses", en Ethnic and Racial Studies, Vol. 29, pp. 104-123.

INE [Instituto Nacional de Estadística], 2011, Censo de población. INEbase: http://www.ine.es.

Kertzer, D.I., Arel, D. (Eds.), 2002, Census and Identity. The politics of race, ethnicity, and language in national census, Cambridge University Press, New York.

Naciones Unidas - Departamento de Asuntos Sociales y Económicos, 2010, Principios y recomendaciones para los censos de población y habitación. Revisión 2, Naciones Unidas, Nueva York.

Nobles, M., 2000, Shades of citinzenship. Race and the census in modern politics, Stanford University Press, Standford.

Lozano Serralta, M., 1955, La nacionalidad en los territorios dependientes: (apuntes sobre la nacionalidad en derecho colonial), Instituto de Estudios Africanos, Madrid.

Peach, C., 1996, "Introduction", en C. Peach (Ed.), Ethnicity in the 1991 Census. Demographic Characteristics of the Minority Populations. Vol. 2, Office for National Statistics, London.

Porter, Th.M., 1996, Trust in Numbers. The Pursuit of Objectivity in Science and Public Life, Princeton University Press, New Jersey.

Ratcliffe, P.B., 1996, "Social Geography and Ethnicity in Britain: Geographical Spread, Spatial Concentration and Internal Migration", en P.B. Ratcliffe (Ed.), Ethnicity in the 1991 Census. Vol. 3, Office for National Statistics, London.

Ratcliffe, P.B., 2008, "'Ethnic Group' and the Population Census in Great Britain: Mission Impossible?", en Ethnic Studies Etniškumo Studijos. Vol. 1. pp. 5-27.

Rivère, M., 2011, "El censo o el dilema entre la realidad y la fantasía", El País, 9 de marzo de 2011, Madrid.

Rodríguez, C.E., 2000, Changing Race. Latinos, the Census and the History of Ethnicity in the United States, New York University Press, New York \& London.

Santamaría, E., 2002, La incógnita del extraño. Una aproximación a la significación sociológica de la "inmigración no comunitaria", Anthropos editorial, Barcelona. 
Simon, P., Piché, V., 2011, "Accounting for ethnic and racial diversity: the challenge of enumeration", en Ethnic and Racial Studies, 35: 8, pp. 1357-1365.

Stallaert, Ch., 1998. Etnogénesis y etnicidad en España. Una aproximación histórica-antropológica al casticismo, Proyecto A, Barcelona.

Watts, R., 2003, "Making numbers count. The birth of the Census and the Racial Government in Victoria, 1835-1840", en Australia Historical Studies, no. 121, pp. 23-47. 